\title{
Diversidade sexual, étnico-racial e de gênero:
}

\author{
temas emergentes
}

Anielly Siqueira Lemes da Silva ${ }^{1}$

O livro Diversidade sexual, étnico-racial e de gênero: temas emergentes, idealizado pela gestão 2019-2020 da Associação Brasileira de Estudos da Homocultura (ABEH) e lançado em 2020 pela Editora Devires, é uma publicação comemorativa de 20 anos da mencionada associação. A obra conta com trabalhos artísticos e acadêmicos de pessoas de várias localidades do país e foi organizada por Brendhon Andrade Oliveira, Bruna Andrade Irineu, Danie Marcelo de Jesus, Gabriel de Oliveira Rodrigues, Guilherme Rodrigues Passamani, Jaqueline Gomes de Jesus, Jefferson Adriã Reis, Luma Nogueira Andrade, Márcio Alessandro Neman do Nascimento, Marco José Duarte, Marcos Aurélio da Silva, Moisés Alessandro Lopes, Pablo Cardozo Rocon e Tatiana Lionço. A apresentação foi escrita por Irineu, Neman do Nascimento, Oliveira e Reis. E o prefácio é de autoria de Fátima Lima.

Dividido em quatro partes, o livro apresenta uma pluralidade de trabalhos que abordam experiências de exercício profissional e/ou de pesquisa e fazem articulações com teorias e conceitos em uma linguagem compreensível para públicos diversos. Essa diversidade salienta o caráter interseccional das áreas de saberes presente nos e entre os estudos, que dizem respeito a identidades, produção de subjetividades, direitos, sociedade, preconceitos e violências, pensados a partir de teorias que compreendem aspectos como gênero, sexualidade, raça/etnia, geração, classe social e econômica etc.

\footnotetext{
${ }^{1}$ Graduanda em Psicologia pela UFR - Universidade Federal de Rondonópolis. Membro da equipe do Laboratório Esquizonalítico de Produção de Subjetividades e(m) Interseccionalidades - LEPSI. E-mail: aniellysiqueira@gmail.com
}

Vol. 03, N. 13, Jan. - Abr., 2021 - http://periodicoscientificos.ufmt.br/ojs/index.php/rebeh/index 
É notável que além dos trabalhos acadêmicos de experiências com pesquisas, trabalhos em instituições, extensões universitárias, entre outros, a obra reúne também textos literários que convidam nos convidam à uma viagem sensível e potente por experiências e vivências afetivas e sexuais dissidentes e/ou singulares, o que evidencia a dedicação da $\mathrm{ABEH}$ em articular a produção acadêmica, ativista e artística. Por meio da arte, é possível começar a leitura de forma leve e ao mesmo tempo movida pelas palavras.

A parte I, A(r)tivismos, memórias e resistências, inicia-se com um capítulo de Irineu, presidenta da ABEH na gestão 2019-2020. No texto, intitulado 20 anos de $A B E H$ : coproduções ativistas, acadêmicas e artísticas, Irineu apresenta os momentos históricos, o engajamento na produção de saberes interseccionais, a militância e a expansão dos trabalhos pelas regiões do Brasil durante duas décadas desde a criação da Associação. Além de percorrer as conquistas, debates, publicações, intervenções e seus impactos no desenvolvimento e avanços de políticas públicas sobre diversidade sexual e de gênero no Brasil, o texto descreve como a ABEH tem se posicionado nessa luta e nos leva a refletir sobre os retrocessos e ataques ocorridos nos últimos anos no país, sentidos, nas universidades, principalmente pela área da pesquisa social e crítica.

Os capítulos subsequentes da primeira seção são compostos por obras literárias. O poema As coisas, de Abayomi Jamila, nos convida como seria se as coisas fossem mais simples. A poeta toca nos toca ao falar sobre amor, rejeição, dor e solidão. Dani Lebinki apresenta três poemas no capítulo seguinte, sendo eles: Dicotomia, Amor proibido e Resquícios. Em uma escrita fluída, Lebinski perambula pelos terrenos da agonia, do sofrimento, do amor e do julgamento.

Francis de Lima Aguiar, em sua micronarrativa A coleira do cão, conta a história de um cão que vive preso a uma corrente que o permite chegar apenas até a sombra. No capítulo seguinte, Joe Sales apresenta um poema e um conto. O poema Do cotidiano na mesa e o conto Quando a macumba pega na gente falam de um modo poético sobre formas de vivência e expressão de amor entre pessoas que deslizam para fora do esperado.

Fechando a sequência de textos literários, o conto Tubaína, de Jefferson Adriã Reis, é uma viagem pela construção subjetiva de um menino do interior que adora desenhar e, no decorrer da narrativa, reflete sobre sua admiração por um garoto mais 
velho, da guarda mirim. O conto retrata o amadurecimento do menino, diante de descobertas e novos sentimentos e sensações.

No capítulo $O$ exercício da parresía no relato de mim mesma: o que se passa comigo ou o que se passa conosco?, Tatiana Lionço discorre, a partir de sua experiência social e pessoal, o conceito de parresía, se apoiando em autores como Judith Butler e Michel Foucault para escrever um relato de si mesma. Lionço retoma os ataques e difamações estabelecidas contra ela e, partindo dos signos desses discursos e ataques, destinados contra sua imagem como professora e psicóloga, procura compreender o que fazer com isso que fizeram/fazem com ela. Ao longo do capítulo, Lionço considera os interesses coletivos e desvenda algumas questões sobre o enredo do fundamentalismo religioso na política nacional.

No capítulo $A$ gestão da ABEH entre o golpe e a "facada", que abre a parte II, Democracia, políticas públicas e direitos, Luma de Andrade, a primeira travesti presidenta da $\mathrm{ABEH}$, conta sua experiência de gestão. A autora faz um recorte temporal dos anos 2017 e 2018, período em que esteve na presidência e em que ocorreram os maiores números de homicídios contra a população LGBTI (Lésbicas, Gays, Bissexuais, Travestis, Transexuais e Intersexuais) no Brasil. Andrade lembra que esse período foi marcado por mudanças sociopolíticas que ganharam força com o golpe sofrido pela expresidenta da República Dilma Rousseff e que culminaram na crescente manipulação política, jurídica e midiática da extrema-direita. A autora ainda comenta a organização de ataques e fake news que resultaram na ascensão de um suposto "Messias", fato que também é retratado em outros capítulos do livro como um grande momento de retrocesso.

Jaqueline Gomes de Jesus, em seu texto Gestão da diversidade no Brasil: notas críticas, faz um apanhado sobre a diversidade e destaca os desafios que são encontrados no desenvolvimento e gestão efetiva da diversidade nos ambientes organizacionais de trabalho no Brasil. A autora reitera diversas leis que asseguram as ações afirmativas que devem ser direcionadas a grupos sócio-historicamente discriminados e marginalizados, como também apresenta o que chama de "Agenda de Diversidade", que abrange de forma muito mais complexa a tarefa de combater discriminações.

No capítulo seguinte, de título Um balanço crítico acerca da regressão dos direitos LGBTI no Brasil sob ascensão do bolsonarismo, Bruna Andrade Irineu, 
Brendhon Oliveira e Milena Lacerda discorrem sobre a explosão da onda de neoliberalismo e neoconservadorismo, que firmam uma nova direita no Brasil, representada atualmente pelo bolsonarismo e que articula um país sem legislação pródireitos LGBTI. Embora muitas políticas pró-direitos da população LGBTI tenham sido criadas décadas atrás, sobretudo nos governos petistas, os autores apontam que existem ambiguidades e contradições entre os governos Lula e Dilma que comprometem o desenvolvimento dessas políticas.

Em A construção da cidadania e das políticas públicas para LGBTs no CentroOeste do Brasil, Moisés Lopes faz um apanhado das pesquisas realizadas acerca da construção de políticas públicas e ações governamentais direcionadas à população LGBT na região Centro-Oeste do país, com foco no estado de Mato Grosso. Lopes ressalta como as pesquisas sobre as diversidades e as ações públicas pelos direitos LGBTs inspiram a realização de outras pesquisas em diversas áreas do conhecimento, como Saúde, Antropologia e Educação, direcionadas a grupos e suas particularidades e especificidades, como saúde de pessoas transexuais e travestis, saúde da mulher lésbica, entre outros.

No capítulo Os aspectos psicossociais do atendimento de mulheres, LGBT+e crianças na Defensoria Pública - Núcleo Criminal do Município de Rondonópolis, Márcio A. Neman do Nascimento, Amanda Almeida, Lissa de Souza e Maria Carolina K. Ferreira relatam a experiência de estágio e extensão de estudantes do Curso de Psicologia da Universidade Federal de Rondonópolis (UFR) que realizaram atendimentos psicossociais na Defensoria Pública do município. O texto explora mais afundo as principais demandas que o serviço de Psicologia encontra na Defensoria, que são os casos de mulheres e crianças vítimas de violência intrafamiliar, sexual e de gênero. Os autores ainda discorrem sobre os atendimentos oferecidos para a população LGBT+.

Marco José Duarte, Dandara Oliveira e Késia Ignácio promovem uma reflexão sobre o conceito de interseccionalidade, no capítulo Gênero, raça e sexualidade: uma proposta de debate interseccional?, que abre a parte III, Alianças, estratégias e ressignificações. Os autores partem da produção de mulheres negras que se questionaram sobre o que lhes atravessava, como Lélia Gonzales, Angela Davis, Sojourner Truth e Carolina de Jesus, que ressaltavam a importância de se interseccionar eixos de 
dominação, como Davis (2016) nomeia, antes mesmo de a interseccionalidade se tornar um conceito.

Em vários capítulos de Diversidade sexual, étnico-racial e de gênero: temas emergentes, é possível observar a dedicação dos autores para que os debates sobre as diversidades aconteçam numa perspectiva interseccional. São posicionamentos como esses que fazem com que as pesquisas, os movimentos e as intervenções realizadas e publicadas nas áreas sociais-críticas deem cada vez mais espaço e importância para a compreensão das violências, discriminações e composições humanas de forma sensível às intersecções.

Em Bruxas, loucas ou más: aborteiras no entre de feitiços e problemas, María Barone, Alexsandro Rodrigues e Pablo Rocon dissertam sobre o aborto e a caça às aborteiras como uma caça às bruxas e realizam uma articulação com autores e autoras que estudam gênero e conhecimentos de povos tradicionais. Os autores investigam a caça às mulheres a partir da história de perseguição de conhecimentos tradicionais, ideias divergentes do capitalismo, do discurso sobre sexo e reprodução, saberes sobre prazer e masturbação, feitiços e magias etc. Nessa discussão, os autores revelam uma caça às bruxas atualizada, com novos formatos, mas com os princípios de impedimento, demonização do aborto e controle do corpo.

No capítulo Corpos em transformação: narrativas de mulheres trans e travestis sobre os sentidos de envelhecer, Ana Paola Lima e Danie de Jesus analisam narrativas de mulheres trans e travestis sobre o envelhecimento a partir de uma abordagem da Linguística Aplicada transgressora e crítica. Chegar à velhice é uma grande conquista para essas populações, um estágio da vida considerado um status social pelas participantes da pesquisa, por significar uma experiência potente de sobrevivência numa sociedade transfóbica e que, consequentemente, cria condições precárias de vida para esses grupos sociais. No Brasil, a expectativa de vida de mulheres transexuais e travestis é de 35 anos.

O capítulo Prostituição masculina em contextos transnacionais: projetos, campos de possibilidades e agência em Lisboa, de Guilherme Passamani, Marcelo Rosa, Jônatas Alaman e Tatiana Lopes, aborda um tema pouco pesquisado no Brasil até então: a prostituição masculina. Os autores analisam experiências de homens brasileiros em suas 
cidades de origem e a ida para Portugal, assim como a forma como a prostituição entrou como um projeto na vida desses homens. As discussões feitas entre pesquisadores e interlocutores trazem uma representação sobre a realidade desse projeto e nos convida a refletir acerca da racialização que traça os desejos nos corpos brasileiros e as relações de poder vigentes.

No texto O funk carioca e o dom de visibilizar culturas e identidades: quando a representatividade transforma o social (?), Benjamin Neves faz análises audiovisuais de músicas funk tendo como referencial conceitos como transfeminismo das masculinidades. Por meio da comparação entre três produções diferentes, Neves reflete sobre os comportamentos atribuídos aos gêneros (binariedade) e sobre presença e representação (ou não) de corpos que estão além da cisheteronormatividade nas produções musicais e visuais.

Em Bricolagem parental: análise cartográfica filmica de filiação na configuração familiar singular apresentada em Patrik 1.5, Lorena de Oliveira e Márcio A. Neman do Nascimento analisam o filme sueco Patrik 1.5, tendo como posicionamento teórico-metodológico a Esquizoanálise, de Gilles Deleuze e Félix Guattari. Os autores abordam questões e discussões sócio-histórico-políticas e culturais sobre família e adoção por famílias homoparentais e problematizam micro e macropolíticas que atravessam famílias fora do modelo tradicional.

Na quarta e última parte da obra, Manifestos por outros futuros possíveis, a turma 2020 do curso Teorias Feministas e Lesbiandades apresenta o texto Manifesta LésbicaFeminista. A leitura desse trabalho coletivo nos leva por caminhos de compreensão acerca da resistência diária pelo direito de amar. O posicionamento da turma é o da luta e o da pesquisa interseccional por uma educação anti-LGBTfóbica, antirracista e anticapitalista.

As autoras Sara Wagner York, Bruna Benevides e Megg Rayara Gomes de Oliveira apresentam o último capítulo, intitulado Manifesto travesti. O texto retrata diversos obstáculos, violências e marginalizações historicamente sofridas por travestis, articula conceitos e, principalmente, faz reivindicações importantes para uma sociedade livre da discriminação e da opressão contra travestis.

Seja por meio de análises de produções audiovisuais, relatos de experiências, intervenções, textos artísticos, análises de narrativas, todos os capítulos culminam em 


\section{줕대뉴 \\ REVISTA BRASILEIRA DE ESTUDOS DA HOMOCULTURA}

discussões que fortalecem o debate sobre a diversidade e encorajam o enfrentamento e a resistência no que tange ao tema diversidade sexual, étnico-racial e de gênero, sobretudo no cenário atual brasileiro de retrocessos, censura, ondas conservadoras, ascensão das concepções do neoliberalismo, do fascismo, do bolsonarismo e sua política de genocídio.

O livro foi escrito por uma miscelânea de mãos e é possível ouvir em suas páginas uma pluralidade de vozes que entregam sensibilidade, análises, críticas e discussões atuais imprescindíveis para a construção de um mundo mais equitativo, respeitoso, solidário e que celebre a diversidade da vida. Qualquer pessoa que se interesse pelos estudos de gênero, diversidades sexuais e relações étnico-raciais, seja da academia ou não, profissional das áreas das Ciências Humanas e Sociais ou não, encontrará na leitura dessa obra um convite para reflexões e novas percepções.

\section{Referência}

IRINEU, et al. (Orgs.). Diversidade sexual, étnico-racial e de gênero: temas emergentes. Salvador: Devires, 2020. Publicação eletrônica.

Recebido: 03/05/2021

Aceito: 30/06/2021 